\title{
Abuse Potential of Synthetic Cannabinoids: AM-1248, CB-13, and PB-22
}

\author{
Kwang-Hyun Hur ${ }^{1, \dagger}$, Shi-Xun Ma, ${ }^{1, \dagger}$, Bo-Ram Lee ${ }^{1}$, Yong-Hyun Ko ${ }^{1}$, Jee-Yeon Seo ${ }^{1}$, Hye Won Ryu ${ }^{2}$, Hye Jin Kim², \\ Seolmin Yoon ${ }^{3}$, Yong-Sup Lee ${ }^{2}$, Seok-Yong Lee ${ }^{1}$ and Choon-Gon Jang ${ }^{1, *}$ \\ ${ }^{1}$ Department of Pharmacology, School of Pharmacy, Sungkyunkwan University, Suwon 16419, \\ ${ }^{2}$ Medicinal Chemistry Laboratory, Department of Pharmacy \& Department of Life and Nanopharmaceutical Sciences, College of \\ Pharmacy, Kyung Hee University, Seoul 02447, \\ ${ }^{3}$ Medicinal Chemistry Laboratory, Department of Fundamental Pharmaceutical Sciences, College of Pharmacy, Kyung Hee \\ University, Seoul 02447, Republic of Korea
}

\begin{abstract}
Currently, the expanding recreational use of synthetic cannabinoids (SCBs) threatens public health. SCBs produce psychoactive effects similar to those of tetrahydrocannabinol, the main component of cannabis, and additionally induce unexpected pharmacological side effects. SCBs are falsely advertised as legal and safe, but in reality, SCB abuse has been reported to cause acute intoxication and addictive disorders. However, because of the lack of scientific evidence to elucidate their dangerous pharmacological effects, SCBs are weakly regulated and continue to circulate in illegal drug markets. In the present study, the intravenous self-administration (IVSA) paradigm was used to evaluate the abuse potential of three SCBs (AM-1248, CB-13, and PB-22) in rats. All three SCBs maintained IVSA with a large number of infusions and active lever presses, demonstrating their reinforcing effects. The increase of active lever presses was particularly significant during the early IVSA sessions, indicating the reinforcementenhancing effects of the SCBs (AM-1248 and CB-13). The number of inactive lever presses was significantly higher in the SCB groups (AM-1248 and CB-13) than that in the vehicle group, indicating their impulsive effects. In summary, these results demonstrated that SCBs have distinct pharmacological properties and abuse potential.
\end{abstract}

Key Words: Synthetic cannabinoids, Abuse potential, Intravenous self-administration, AM-1248, CB-13, PB-22

\section{INTRODUCTION}

Cannabis, also known as marijuana, is one of the oldest psychoactive drugs and is widely used for recreational purposes (Carliner et al., 2017; Lawler, 2018). Cannabis is abused because of its psychological effects (e.g., relaxation, euphoria, and mind alteration), which are largely attributed to tetrahydrocannabinol (THC), its main psychoactive component (Osborne and Fogel, 2008; Murray et al., 2017). As the pharmacological effects of THC have been revealed (Gaoni and Mechoulam, 1964), synthetic cannabinoids (SCBs) have been developed to mimic those effects (Weissman et al., 1982).

SCBs were initially developed as laboratory research tools to investigate the cannabinoid system (Melvin et al., 1993). SCBs have been available on the illegal drug market since the early 2000s, and they are often used for recreational pur- poses (Papaseit et al., 2014). Since SCBs produce psychoactive effects similar to those of THC, the use of some SCBs has been legally restricted (Berkovitz et al., 2011). However, new analogs, which have alterations to their chemical structure to avoid these restrictions, are continually emerging (Angerer et al., 2018; Krotulski et al., 2019). These drugs are sprayed on plant material and commercialized in herbal mixtures, creating the misinterpretation that these synthetic products are natural and safe (Dresen et al., 2010). Additionally, false advertising, which claims that the use of these SCBs is legal and causes temporary euphoria without the risk of addiction, encourages their recreational use (Sarıbaş and Ulugöl, 2014). However, indeed, SCB use has caused unpredictable adverse effects, resulting in severe physical and psychological disabilities (Hermanns-Clausen et al., 2013b; Behonick et al., 2014).

Most case reports have linked the use of SCBs to acute

\section{Open Access https://doi.org/10.4062/biomolther.2020.212}

This is an Open Access article distributed under the terms of the Creative Commons Attribution Non-Commercial License (http://creativecommons.org/licenses/by-nc/4.0/) which permits unrestricted non-commercial use, distribution, and reproduction in any medium, provided the original work is properly cited.
Received Nov 25, 2020 Revised Feb 17, 2021 Accepted Mar 22, 2021 Published Online May 3, 2021

\section{*Corresponding Author}

E-mail: jang@skku.edu

Tel: +82-31-290-7780, Fax: +82-31-292-8800

${ }^{\dagger}$ The first two authors contributed equally to this work. 
intoxication, such as hypertension, tachycardia, seizure, amnesia, and unconsciousness (Heath et al., 2012; HermannsClausen et al., 2013a). By contrast, very few case reports have evaluated SCB abuse and potential addiction (Grigg et al., 2019). And consequently, drug risk assessment has only focused on the toxic effects of drugs that can cause an emergency, whereas the abuse potential of drugs, which can be a primary cause of psychotropic drug abuse, is often overlooked.

Drug addiction is an expected consequence of drug abuse with a reinforcing effect (Wise and Koob, 2014). Even after one use of the drug, the memory of the euphoric experience can lead to compulsive drug cravings. The addicts typically lose control and continue to chronically use the drug despite the harm it inflicts. They may try to quit using the drug after suffering from severe mental and physical illness, but quitting is impossible because of severe withdrawal syndrome (Budney and Hughes, 2006). Therefore, we consider the abuse potential of drugs to be the initial trigger of drug-related diseases and the most dangerous characteristic associated with risk assessment.

Many cases of SCB addiction have been reported worldwide (Inci et al., 2017). Several withdrawal symptoms such as craving, anxiety, headache and insomnia have been observed in SCB addicts (Zimmermann et al., 2009; Nacca et al., 2013). These dependence on SCB is considered to be due to its potent agonist activity on the cannabinoid receptor 1 (CB1), which is responsible for the psychoactive effects of cannabinoids (Tai and Fantegrossi, 2014). In particular, activation of the CB1 specifically activates the dopaminergic system of the brain reward circuit, which can lead to drug addiction (Covey et al., 2015). Therefore, SCBs with strong affinity for the CB1 must be warned of their abuse potential.

AM-1248, CB-13, and PB-22 are SCBs with their own unique chemical structures (Fig. 1). All three are known to act as potent agonists on the CB1 receptor (Dziadulewicz et al., 2007; Makriyannis and Deng, 2007; Banister et al., 2015), but little is known about their pharmacological effects. In many countries, their recreational use has been legally regulated (Uchiyama et al., 2012; Drug Enforcement Administration, Department of Justice, 2016), but they are still found in herbal blends sold for recreational use in illegal drug markets (Aldlgan, 2016; Dei Cas et al., 2019; Burns et al., 2020). This is due to the lack of scientific evidence of their abuse potential, which is necessary for the strict regulation of these SCBs. Therefore, in the present study, we examined the addictive potential of these three SCBs through the intravenous self-administration (IVSA) test, which is the most validated experimental method for evaluating drug abuse liability in animals.

\section{MATERIALS AND METHODS}

\section{Animals}

Male Sprague Dawley rats were acquired from Orient Bio Co., Ltd. (Seoul, Korea) for the self-administration (SA) test. The rats were housed two per cage in a constant temperature- and humidity-controlled room $\left(23^{\circ} \mathrm{C} \pm 1^{\circ} \mathrm{C}\right.$ and $55 \% \pm$ $5 \%$ ) under a $12 \mathrm{~h}$ light/dark cycle (light on between 7 a.m. and 7 p.m.). The experiment began 1 week after their arrival and occurred at the same time each day during the light phase of the cycle (between 9 a.m. and 2 p.m.). The rats had free access to food and water, except during food training sessions, and weighed between 270 and $320 \mathrm{~g}$ at the start of the experiment. All animal care procedures were conducted according to the U.S. National Institutes of Health Guide and the Institute for Laboratory Animal Research Guidelines for the Care and Use of Laboratory Animals, and were approved by the Institutional Animal Care and Use Committee of the Sungkyunkwan University. All efforts were made to minimize animal suffering, to reduce the number of animals used, and to utilize alternatives to in vivo techniques, if available.

\section{Drugs}

AM-1248, CB-13, and PB-22 were synthesized and provided by Professor Yong Sup Lee at the Medicinal Chemistry Laboratory, Department of Pharmacy, and Department of Life and Nanopharmaceutical Sciences, College of Pharmacy, Kyung Hee University (Seoul, Korea). The selection of drug dose-range was based on previous studies (Fattore et al., 2001; Spano et al., 2004). These drugs were dissolved in the vehicle (5\% dimethyl sulfoxide, $5 \%$ Tween $80,90 \%$ physiological saline) and administered to the rats intravenously (i.v.) in a volume of $0.1 \mathrm{~mL}$ per injection.

\section{Intravenous SA (IVSA)}

The IVSA test was performed with a slight modification of the previously reported experimental designs to evaluate the reinforcing effect of SCBs (Hur et al., 2020). The specific experimental procedure is shown in Fig. 2.

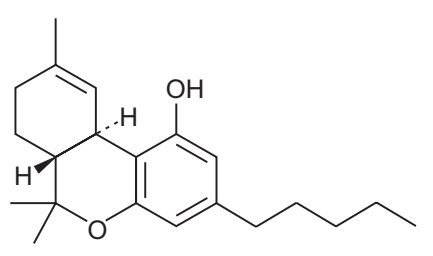

THC

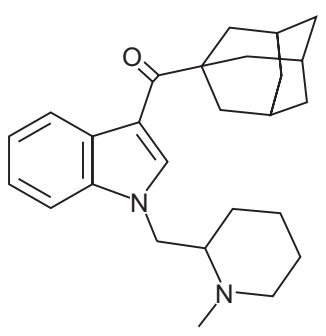

AM-1248

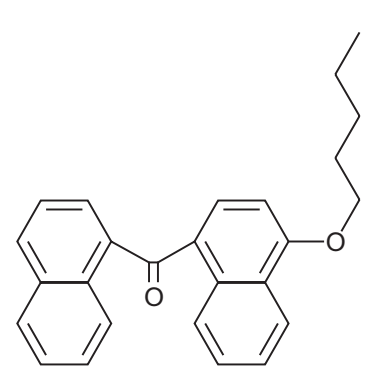

CB-13<smiles>CCCCCn1cc(C(=O)Oc2cccc3cccnc23)c2ccccc21</smiles>

PB-22

Fig. 1. Depiction of structures: tetrahydrocannabinol (THC), AM-1248, CB-13, and PB-22. 


\begin{tabular}{|c|c|c|c|c|}
\hline Habituation & Food training & Surgery & Recovery & $\begin{array}{l}\text { Intravenous self-administration (IVSA) } \\
\text { Fixed ratio } 1 \text { (FR1) schedule for } 2 \text { hours a day }\end{array}$ \\
\hline 7 days & 3 days & 2 days & 7 days & 7 days \\
\hline
\end{tabular}

Fig. 2. Diagrams outlining the experimental schedule of the intravenous self-administration (IVSA) test.

\section{Apparatus}

During experimental sessions, each rat was tested in a standard operant chamber, which was placed inside a lightand sound-attenuating cubicle $(28 \times 26 \times 20 \mathrm{~cm}$; Med Associates Inc., St. Albans, VT, USA). Each chamber was equipped with response levers $(4.8 \times 1.9 \mathrm{~cm})$, a cue light ( $3 \mathrm{~W}, 28 \mathrm{~V})$, and a house light $(3 \mathrm{~W}, 28 \mathrm{~V})$. A cue light was positioned above each response lever. The front door and the back wall of the chamber were made of transparent plastic, and the other walls were made of an opaque metal. Drug injections were delivered via a syringe pump (Razel Scientific Instruments, Georgia, VT, USA) located on top of the cubicle. The experimental sessions were controlled and recorded in the experimental room using a PC with a custom interface and software.

\section{Food training}

To facilitate the acquisition of operant responding, the rats were initially trained to press a lever to receive $45 \mathrm{mg}$ of food pellets (Bio-Serv, Flemington, NJ, USA). The rats were deprived of food for $12 \mathrm{~h}$ prior to training and were then trained in $1 \mathrm{~h}$ daily sessions in standard operant chambers until criteria were satisfied (80 food pellets for three consecutive days).

\section{Intravenous catheterization}

Prior to surgery, rats were anesthetized with pentobarbital anesthesia (50 mg/kg, intraperitoneal). A silastic catheter (0.3 mm i.d. $\times 0.64 \mathrm{~mm}$ o.d.; Dow Corning Co., Midland, MI, USA) was implanted into the right external jugular vein and secured with Mersilene surgical mesh (Ethicon Inc., Somerville, NJ, USA). The rats were injected with $0.2 \mathrm{~mL}$ of the antibiotic gentamicin sulfate $(0.32 \mathrm{mg} / \mathrm{mL}$; Kukje Pharma Co., Seongnam, Korea) in heparinized saline $(20 \mathrm{lU} / \mathrm{mL})$ and allowed to recover for 5 days before IVSA testing began.

\section{Intravenous SA (IVSA) test}

After their recovery from surgery, animals were randomly placed into four groups for the drug IVSA test: a vehicle SA group as a negative control and three drug IVSA groups (3, 10 , and $30 \mu \mathrm{g} / \mathrm{kg} /$ infusion). The drug IVSA test was performed under a fixed ratio 1 (FR1) schedule of reinforcement for $2 \mathrm{~h}$ per day for seven consecutive days. During the experimental sessions, each rat was placed in a standard operant chamber (Med Associates Inc.) and the catheters were connected to tubing suspended from a balance arm above the chambers. The house light was turned on at the start of each session, and two levers were placed in the chamber: the right lever was designated as the active lever, and the left lever was designated as the inactive lever. Pressing the right lever resulted in the delivery of $0.1 \mathrm{~mL}$ of a drug solution over $4 \mathrm{~s}$ via a syringe pump. The house light was turned off during injection, and a cue light above the right lever was illuminated during the time-out period (approximately $20 \mathrm{~s}$ ) that followed each injection. Pressing the right lever during this period did not initiate any response, but the number of lever presses was still recorded. The cue light was turned off at the end of the timeout period, and the house light was turned on, signaling that the next injection was possible. Pressing the left lever had no programmed consequences but was still recorded. Sessions were ended by withdrawing the two levers.

\section{Statistical analysis}

To evaluate the reinforcing effects of the SCBs, the number of infusions, active lever presses, and inactive lever presses in the IVSA test were measured over a $2 \mathrm{~h}$ period. Data were analyzed by researchers who were blind to the agent administered, and the results were expressed as the mean \pm standard error of the mean (SEM). Daily response data were analyzed using two-way repeated-measures ANOVA (with drug treatment, day, and their interaction as independent factors) followed by Fisher's least significant difference (LSD) post hoc test. Average data were analyzed using one-way ANOVA followed by Fisher's LSD post hoc test. All analyses were performed using Prism 6.0 software (GraphPad Software, Inc., San Diego, CA, USA). A $p$ value of less than $0.05(p<0.05)$ indicated statistical significance.

\section{RESULTS}

\section{AM-1248 increased SA in rats}

Fig. 3A shows the number of infusions during the daily IVSA sessions. AM-1248 significantly increased the number of infusions (3 $\mu \mathrm{g} / \mathrm{kg} /$ infusion group in sessions 1,2 , and 3; $10 \mu \mathrm{g} /$ $\mathrm{kg} /$ infusion group in session $1 ; 30 \mu \mathrm{g} / \mathrm{kg} /$ infusion group in all sessions) compared with the number recorded with the vehicle. Accordingly, the average of the total number of infusions expressed in Fig. 3D was significantly higher in all AM-1248 groups than the average in the vehicle group $\left[F_{(3,16)}=13.71\right.$, $\left.P_{3}<0.05, P_{10}<0.05, P_{30}<0.05\right]$.

Fig. 3B shows the number of active lever presses during the daily IVSA sessions. AM-1248 also significantly increased the number of active lever presses $(3 \mu \mathrm{g} / \mathrm{kg} /$ infusion group in sessions 1,2 , and $3 ; 10 \mu \mathrm{g} / \mathrm{kg} /$ infusion group in session $1 ; 30$ $\mu \mathrm{g} / \mathrm{kg} /$ infusion group in sessions $1,2,3$, and 7) compared with the number recorded with the vehicle. Accordingly, the average of the total active lever presses expressed in Fig. 3E was significantly higher in all $\mathrm{AM}-1248$ groups than the average in the vehicle group $\left[F_{(3,16)}=14.30, P_{3}<0.05, P_{10}<0.05, P_{30}<0.05\right]$.

Fig. $3 \mathrm{C}$ shows the number of inactive lever presses during the daily IVSA sessions. AM-1248 also significantly increased the number of inactive lever presses $(3 \mu \mathrm{g} / \mathrm{kg} / \mathrm{infusion}$ group on sessions 1,2 , and $3 ; 10 \mu \mathrm{g} / \mathrm{kg} /$ infusion group on sessions 1,2 , and $4 ; 30 \mu \mathrm{g} / \mathrm{kg} /$ infusion group on all sessions) compared with the number recorded with the vehicle. Accordingly, the average of the total inactive lever presses expressed in Fig. $3 \mathrm{~F}$ was significantly higher in all $\mathrm{AM}-1248$ groups than the average in the vehicle group $\left[\mathrm{F}_{(3,16)}=8.53, \mathrm{P}_{3}<0.05, \mathrm{P}_{10}<0.05\right.$, $\left.\mathrm{P}_{30}<0.05\right]$. 

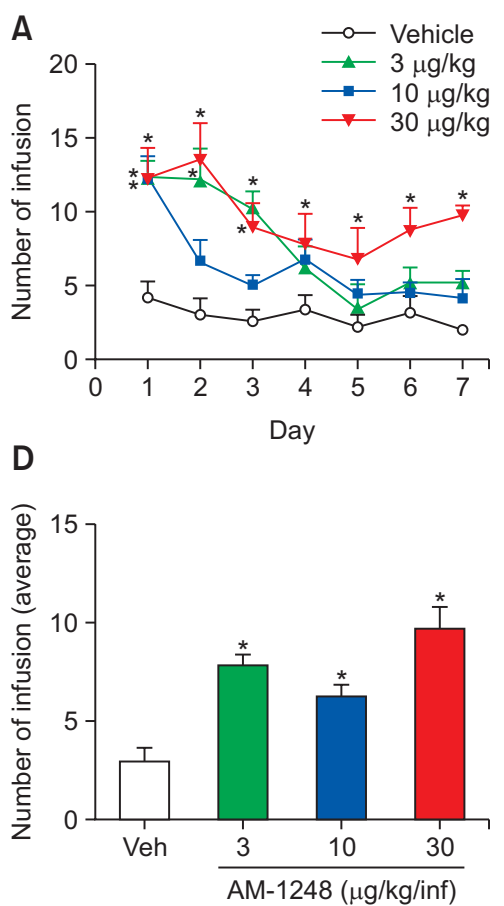
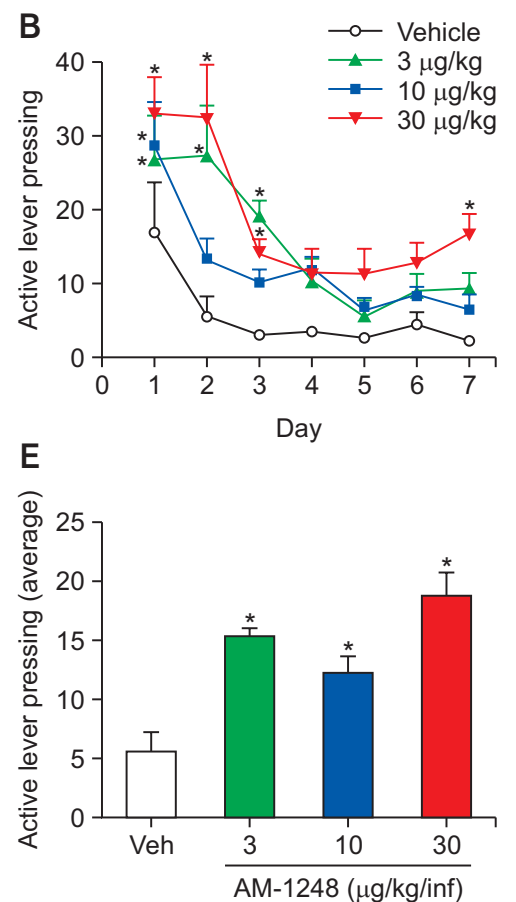
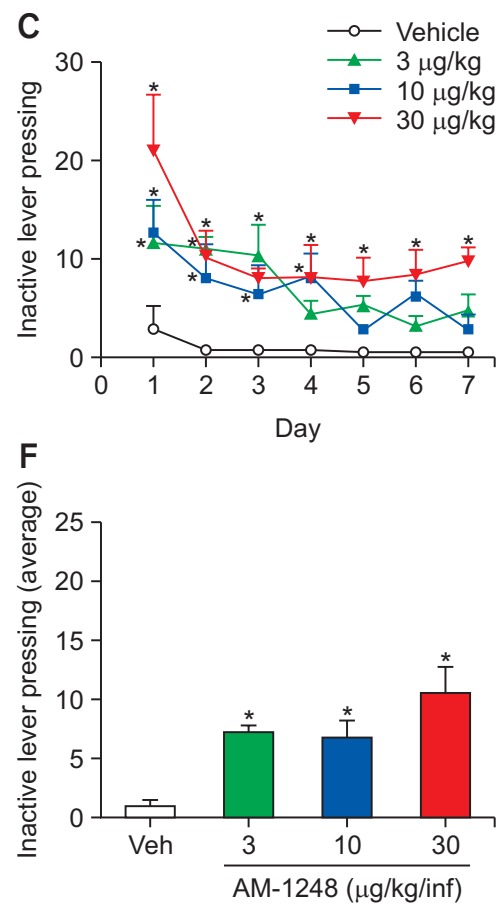

Fig. 3. Effect of $A M-1248$ on intravenous self-administration (IVSA) in rats ( $n=5$ per group). Each group of rats self-administered vehicle or AM-1248 (3, 10, and $30 \mu \mathrm{g} / \mathrm{kg} /$ infusion) under a FR1 schedule for seven consecutive days. All drugs were injected intravenously at a volume of $0.1 \mathrm{~mL} /$ infusion. (A) Number of infusions during a daily session. (B) Number of active lever presses during a daily session. (C) Number of inactive lever presses during a daily session. (D) Average total number of infusions over 7 days. (E) Average total number of active lever presses over 7 days. (F) Average total number of inactive lever presses over 7 days. Data are presented as means \pm SEMs. Significant differences between the vehicle group and the AM-1248 groups are indicated by * $p<0.05$.

\section{CB-13 increased SA in rats}

Fig. 4A shows the number of infusions during the daily IVSA sessions. CB-13 significantly increased the number of infusions $(3 \mu \mathrm{g} / \mathrm{kg} /$ infusion group in session $1 ; 10 \mu \mathrm{g} / \mathrm{kg} / \mathrm{infusion}$ group in sessions 1 and $3 ; 30 \mu \mathrm{g} / \mathrm{kg} /$ infusion group in sessions 1 and 2) compared with the number recorded with the vehicle. Accordingly, the average of the total number of infusions expressed in Fig. 4D was significantly higher in all CB-13 groups than the average in the vehicle group $\left[F(3,16)=12.70, P_{3}<0.05\right.$, $\left.\mathrm{P}_{10}<0.05, \mathrm{P}_{30}<0.05\right]$.

Fig. 4B shows the number of active lever presses during the daily IVSA sessions. CB-13 also significantly increased the number of active lever presses $(3 \mu \mathrm{g} / \mathrm{kg} /$ infusion group in session $1 ; 10 \mu \mathrm{g} / \mathrm{kg} /$ infusion group in session $1 ; 30 \mu \mathrm{g} / \mathrm{kg} / \mathrm{infu}-$ sion group in sessions 1 and 2) compared with the number recorded with the vehicle. Accordingly, the average of the total active lever presses expressed in Fig. 4E was significantly higher in all CB-13 groups than the average in the vehicle group $\left[F_{(3,16)}=9.98, P_{3}<0.05, P_{10}<0.05, P_{30}<0.05\right]$.

Fig. 4C shows the number of inactive lever presses during the daily IVSA sessions. CB-13 also significantly increased the number of inactive lever presses ( $3 \mu \mathrm{g} / \mathrm{kg} /$ infusion group in session $1 ; 10 \mu \mathrm{g} / \mathrm{kg} / \mathrm{infusion}$ group in session $1 ; 30 \mu \mathrm{g} / \mathrm{kg} / \mathrm{infusion}$ group in session 1) compared with the number recorded with the vehicle. Accordingly, the average of the total inactive lever presses expressed in Fig. 4F was significantly higher in all $\mathrm{CB}-$ 13 groups than the average in the vehicle group $\left[F_{(3,16)}=7.6\right.$, $\left.P_{3}<0.05, P_{10}<0.05, P_{30}<0.05\right]$.

\section{PB-22 increased SA in rats}

Fig. 5A shows the number of infusions during the daily IVSA sessions. PB-22 significantly increased the number of infusions ( $3 \mu \mathrm{g} / \mathrm{kg} /$ infusion group in all sessions; $10 \mu \mathrm{g} / \mathrm{kg} /$ infusion group in sessions 1 and 7) compared with the number recorded with the vehicle. Accordingly, the average of the total number of infusions expressed in Fig. 5D was significantly higher in the PB-22 groups ( $3 \mu \mathrm{g} / \mathrm{kg} /$ infusion group; $10 \mu \mathrm{g} / \mathrm{kg} /$ infusion group) than the average in the vehicle group $\left[F_{(3,16)}=9.41, P_{3}<0.05\right.$, $\left.\mathrm{P}_{10}<0.05, \mathrm{P}_{30}>0.05\right]$.

Fig. 5B shows the number of active lever presses during the daily IVSA sessions. PB-22 also significantly increased the number of active lever presses ( $3 \mu \mathrm{g} / \mathrm{kg} /$ infusion group in sessions 5,6 , and $7 ; 10 \mu \mathrm{g} / \mathrm{kg} /$ infusion group in sessions 1 and 6) compared with the number recorded with the vehicle group. Accordingly, the average of the total active lever presses expressed in Fig. 5E was significantly higher in the PB22 groups ( $3 \mu \mathrm{g} / \mathrm{kg} /$ infusion group; $10 \mu \mathrm{g} / \mathrm{kg} /$ infusion group) than the average in the vehicle group $\left[F_{(3,16)}=5.9, P_{3}<0.05\right.$, $\left.\mathrm{P}_{10}<0.05, \mathrm{P}_{30}>0.05\right]$.

Fig. $5 \mathrm{C}$ shows the number of inactive lever presses during the daily IVSA sessions. There was no significant difference in the number of inactive lever presses between the PB-22 groups and the vehicle group. Accordingly, there was no significant difference in the average of the total inactive lever presses (Fig. 5F) between the PB-22 groups and the vehicle group $\left[F_{(3,16)}=0.69, P_{3}>0.05, P_{10}>0.05, P_{30}>0.05\right]$. 
A

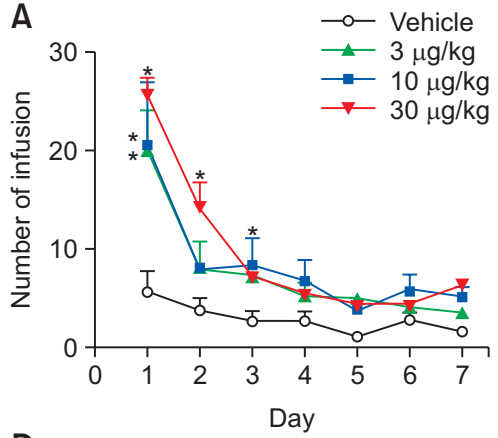

D

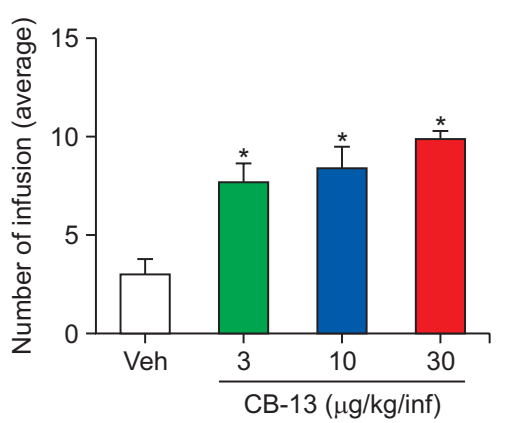

B

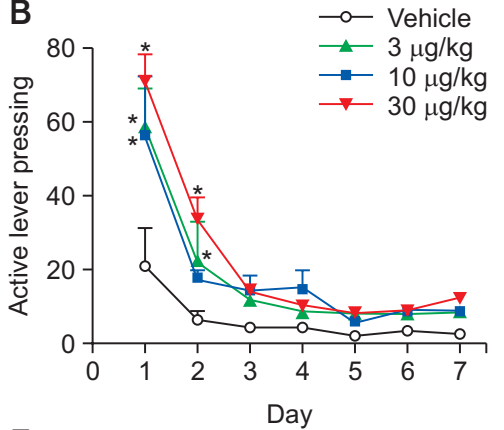

E

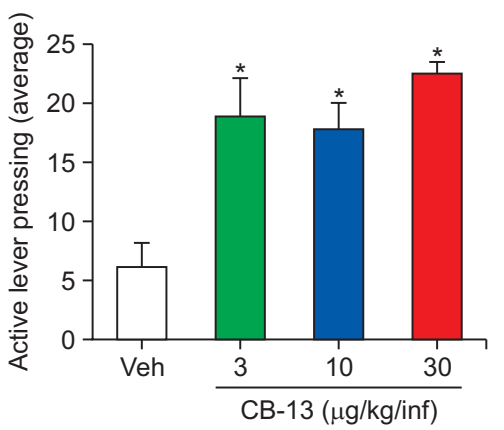

C

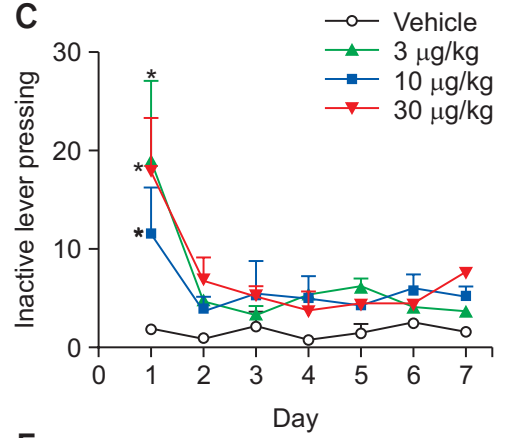

$\mathrm{F}$

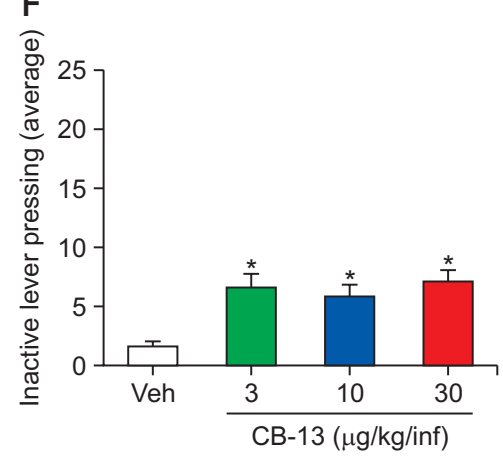

Fig. 4. Effect of $C B-13$ on intravenous self-administration (IVSA) in rats ( $n=5$ per group). Each group of rats self-administered vehicle or CB-13 $(3,10$, and $30 \mu \mathrm{g} / \mathrm{kg} /$ infusion) under a FR1 schedule for seven consecutive days. All drugs were injected intravenously at a volume of $0.1 \mathrm{~mL} /$ infusion. (A) Number of infusions during a daily session. (B) Number of active lever presses during a daily session. (C) Number of inactive lever presses during a daily session. (D) Average total number of infusions over 7 days. (E) Average total number of active lever presses over 7 days. (F) Average total number of inactive lever presses over 7 days. Data are presented as means \pm SEMs. Significant differences between the vehicle group and the CB-13 groups are indicated by ${ }^{*} p<0.05$.

\section{DISCUSSION}

In the present study, the IVSA paradigm was applied as a representative experiment for drug addiction research to evaluate the addictive potential of three SCBs (AM-1248, CB-13, and PB-22).

We found that all three SCBs supported IVSA with an increased number of infusions. These results are consistent with previous reports that SCBs maintained IVSA, demonstrating their reinforcing effects (De Luca et al., 2015; Kirschmann et al., 2017). Considering that THC does not maintain reliable IVSA in rodent (Lefever et al., 2014), it can be assumed that these SCBs have a stronger reinforcing effect than THC. This assumption is supported by case reports that note that, although the development of THC dependence is rare (Carlini, 2004), chronic use of SCBs can lead to dependence (Zimmermann et al., 2009). This difference in pharmacological effects may be due to the difference in pharmacodynamic properties between THC and SCB. First, these three SCBs, as well as most SCBs, have a much higher potency and efficacy against cannabinoid receptors than THC (Dziadulewicz et al., 2007; Makriyannis and Deng, 2007; Banister et al., 2015), which can have stronger psychotic effects than THC. Second, these SCBs, which have distinctly different structures than THC (Fig. 1), may act on non-cannabinoid receptors, such as serotonin, acetylcholine, opioid, and glutamatergic receptors (Hájos et al., 2001; Pertwee et al., 2010), causing unpredictable psychotic effects that are not observed with THC. Although more research is needed to elucidate the mechanisms that enhance the reinforcing effect of SCB, through this study, we have demonstrated that three SCBs have strong addictive potential.

Active lever pressing is a reward-related operant behavior, which is highly established during IVSA if the drug acts as a reinforcement. This behavior was often observed, even in the vehicle group, in the early IVSA sessions when reward-related memories formed during food training (Table 1). In the meantime, the $\mathrm{AM}-1248$ and $\mathrm{CB}-13$ groups demonstrated their reinforcement-enhancing effects by having many more active lever presses than those in the vehicle group in the early sessions. This may be because SCB's reinforcement-enhancing effects activated the reward circuit formed during food training. This supportive reinforcing effect, which promotes the abuse of other psychotropic substances, has also been confirmed in THC (Solinas et al., 2005). Considering that SCBs are commercialized as a complex mixture (Langer et al., 2014), these synergistic effects can be said to be the most critical pharmacological effects of SCBs in terms of augmenting each other's abuse potential. In the late IVSA sessions, all SCB groups had significantly more active lever presses than those in the vehicle group, which represents a direct reinforcing effect of the SCBs. These results indicate that SCBs have a dual reinforcing effect (supportive and direct), which has also been reported regarding other addictive substances (Brianna Sheppard et al., 2012; Garcia et al., 2014).

The low number of inactive lever presses is presented as a control to demonstrate that rats pressed the active lever as a drug seeking behavior. In all groups, the lever discrimination ratio was predominantly higher for active than for inac- 

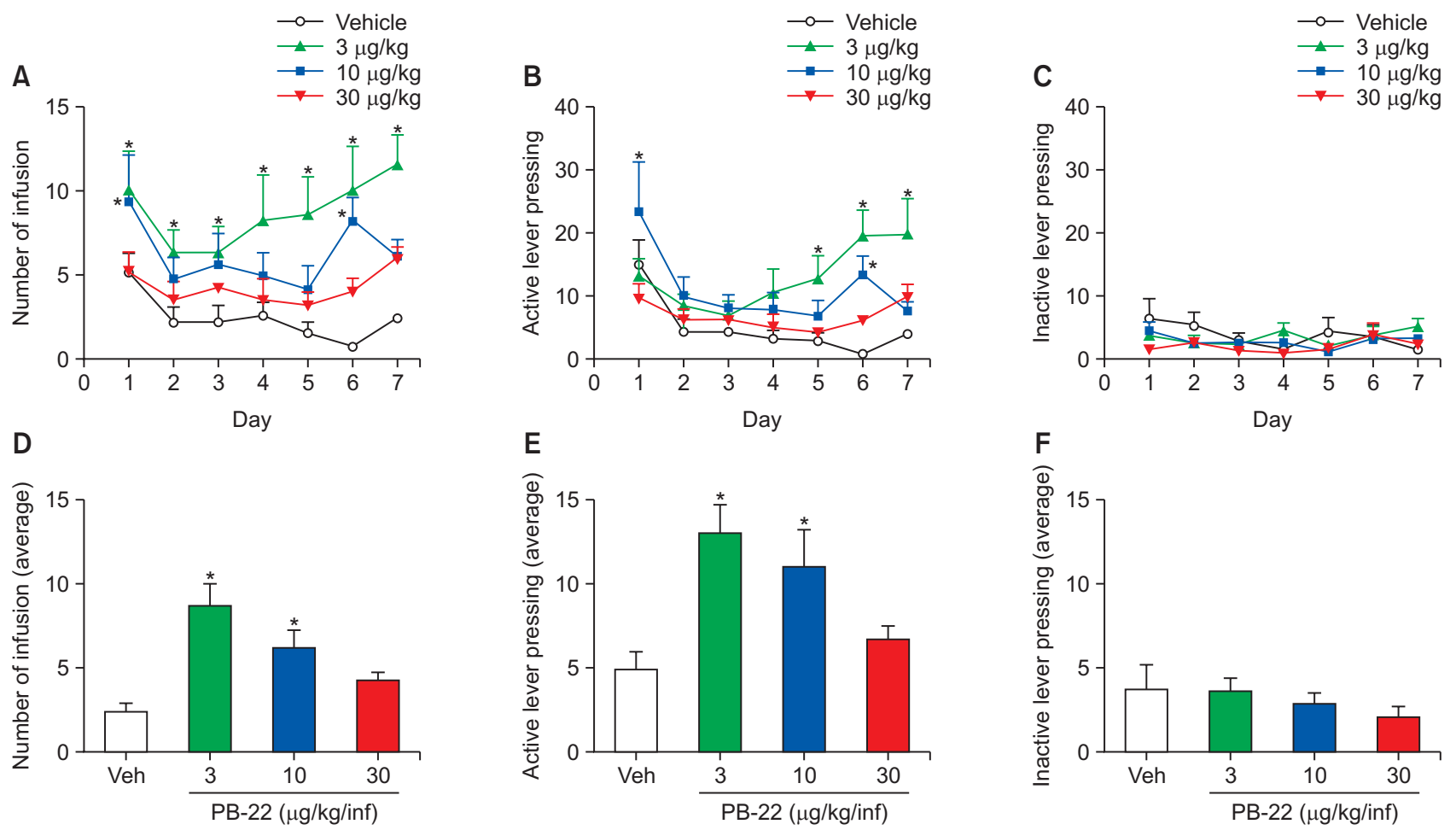

Fig. 5. Effect of PB-22 on intravenous self-administration (IVSA) in rats ( $n=5$ per group). Each group of rats self-administered vehicle or PB-22 $(3,10$, and $30 \mu \mathrm{g} / \mathrm{kg} /$ infusion) under a FR1 schedule for seven consecutive days. All drugs were injected intravenously at a volume of $0.1 \mathrm{~mL} /$ infusion. (A) Number of infusions during a daily session. (B) Number of active lever presses during a daily session. (C) Number of inactive lever presses during a daily session. (D) Average total number of infusions over 7 days. (E) Average total number of active lever presses over 7 days. (F) Average total number of inactive lever presses over 7 days. Data are presented as means \pm SEMs. Significant differences between the vehicle group and the PB-22 groups are indicated by ${ }^{*} p<0.05$.

Table 1. Number of active lever presses during early and late IVSA test sessions

\begin{tabular}{lcc}
\hline \multicolumn{3}{c}{ Active lever presses (means \pm SEMs) } \\
\hline & $\begin{array}{c}\text { Early sessions } \\
\text { (days 1 and 2) }\end{array}$ & $\begin{array}{c}\text { Late sessions } \\
\text { (days 6 and 7) }\end{array}$ \\
\hline Vehicle $^{\mathrm{a}}$ & $9.7 \pm 2.71$ & $2.3 \pm 0.41$ \\
$\mathrm{AM}-1248(30 \mu \mathrm{g} / \mathrm{kg} / \mathrm{inf})$ & $32.7 \pm 5.67^{*}$ & $14.8 \pm 2.16^{*}$ \\
$\mathrm{CB}-13(30 \mu \mathrm{g} / \mathrm{kg} / \mathrm{inf})$ & $52.3 \pm 1.88^{*}$ & $10.4 \pm 1.57^{*}$ \\
PB-22 $(3 \mu \mathrm{g} / \mathrm{kg} / \mathrm{inf})$ & $10.9 \pm 2.02$ & $19.6 \pm 2.86^{*}$ \\
\hline
\end{tabular}

${ }^{\mathrm{a}}$ The control group of the PB-22 group was used as a representative.

*Significant differences between the vehicle group and SCB groups are indicated $(p<0.05)$.

tive presses, demonstrating reasonable IVSA. Meanwhile, the AM-1248 and CB-13 groups displayed significantly higher numbers of inactive lever presses than the vehicle group. These results may reflect that the administration of these SCBs triggered impulsive behavior, which has been commonly observed in SCB users (Ozten et al., 2015; Altıntaş et al., 2019). Additionally, these impulsive effects of SCBs are supported by previous studies that cannabinoid receptors are responsible for impulsive behavior (Leffa et al., 2019; Wiskerke et al., 2012).
Table 2. Number of infusions during daily IVSA test sessions

\begin{tabular}{|c|c|c|c|c|}
\hline & \multicolumn{4}{|c|}{ Infusions (means \pm SEMs) } \\
\hline & Vehicle $^{a}$ & $\begin{array}{c}\text { AM-1248 } \\
(30 \mu \mathrm{g} / \mathrm{kg} / \mathrm{inf})\end{array}$ & $\begin{array}{c}\text { CB-13 } \\
(30 \mu g / k g / i n f)\end{array}$ & $\begin{array}{c}\text { PB-22 } \\
(3 \mu g / k g / i n f)\end{array}$ \\
\hline Day 1 & $5.2 \pm 1.11$ & $12.2 \pm 2.13^{*}$ & $25.8 \pm 1.56^{*}$ & $10.2 \pm 2.18^{*}$ \\
\hline Day 2 & $2.2 \pm 0.92$ & $13.6 \pm 2.4^{*}$ & $14.2 \pm 2.63^{*}$ & $6.4 \pm 1.29$ \\
\hline Day 3 & $2.2 \pm 1.02$ & $9 \pm 1.61^{*}$ & $7.2 \pm 0.73^{*}$ & $6.4 \pm 1.50$ \\
\hline Day 4 & $2.6 \pm 0.81$ & $7.8 \pm 2.08^{*}$ & $5.6 \pm 0.51$ & $8.2 \pm 2.75^{*}$ \\
\hline Day 5 & $1.6 \pm 0.6$ & $6.8 \pm 2.13^{*}$ & $4.4 \pm 0.4$ & $8.6 \pm 2.25^{*}$ \\
\hline Day 6 & $0.8 \pm 0.37$ & $8.8 \pm 1.5^{*}$ & $4.4 \pm 0.75$ & $10 \pm 2.65^{*}$ \\
\hline Day 7 & $2.4 \pm 0.2449$ & $9.8 \pm 0.66^{*}$ & $6.4 \pm 0.93$ & $11.6 \pm 1.75^{*}$ \\
\hline
\end{tabular}

${ }^{\mathrm{a}}$ The control group of the PB-22 group was used as a representative.

*Significant differences between the vehicle group and SCB groups are indicated $(p<0.05)$.

Through a comprehensive comparison of the infusion patterns during the daily IVSA test, we discovered that each SCB had a distinct pharmacological effect (Table 2). First, the AM1248 group (30 $\mu \mathrm{g} / \mathrm{kg} /$ infusion) maintained the most stable IVSA with a consistently high infusion number compared with the vehicle group during the daily IVSA session for 7 days. Meanwhile, the CB-13 group ( $30 \mu \mathrm{g} / \mathrm{kg} /$ infusion) showed a high number of infusions only in the early IVSA sessions (Day 
1-3). This may be due to the accumulation of $C B-13$ through daily drug intake, inducing high concentrations of $\mathrm{CB}-13$, which can lead to cannabimimetic aversive effects, in the late IVSA sessions. This assumption is supported by previous studies that note that high concentrations of CB-13 treatment resulted in negative responses such as catalepsy, hypothermia, and hypomotility (Dziadulewicz et al., 2007; Pryce and Baker, 2017). Lastly, the PB-22 group ( $3 \mu \mathrm{g} / \mathrm{kg} /$ infusion) maintained IVSA stably with high infusion number in the late IVSA session (Days 4-7). As a notable difference from other drugs, PB-22 maintained IVSA in the low-dose administration group $(3 \mu \mathrm{g} /$ $\mathrm{kg} /$ infusion), but not in the high dose administration group (30 $\mu \mathrm{g} / \mathrm{kg} /$ infusion). Considering a previous study that revealed that PB-22 causes dose-dependent depressant effects (Gatch and Forster, 2015), the high dose of PB-22 may have suppressed IVSA through a stronger aversion effect than reinforcing effect. In summary, through these analyses, we found that each SCB not only has a unique molecular structure but also induces a distinct pharmacological effect. These differences may be due to various factors, such as differences in affinity for cannabinoid receptors, unique cell signaling through noncannabinoid receptors, or differences in bioavailability and other pharmacokinetic parameters (Fantegrossi et al., 2014, 2018). Therefore, further studies are needed to determine the exact pharmacological effects of each SCB.

In the present study, we demonstrated that SCBs have reinforcing effects, reinforcement-enhancing effects, and impulsive effects in rodents. Based on these scientific confirmations of the pharmacological effects of SCB, recreational abuse of SCB should be strictly regulated by law, and users should be aware that SCBs are dangerous and illegal drugs that can cause variable side effects and severe addiction.

\section{CONFLICT OF INTEREST}

The authors have no conflicts of interest to declare.

\section{ACKNOWLEDGMENTS}

This research was supported by grants from the Korea Food and Drug Administration (14182MFDS979, 19182MFDS403) and the National Research Foundation of Korea (2017R1A2B2002428) funded by the Korean government.

\section{REFERENCES}

Aldlgan, A. (2016) Chromatographic Analysis and Survey Studies to Evaluate the Emerging Drugs of Synthetic Cannabinoids in Scotland and Saudi Arabia. University of Glasgow.

Altıntaş, M., İnanç, L., Hunca, A. N., Ektiricioğlu, C., Yılmaz, N., Tuna, Z. O. and Üney, R. (2019) Theory of mind, aggression and impulsivity in patients with synthetic cannabinoid use disorders: a casecontrol study. Anadolu Psikiyatri Derg. 20, 5-12.

Angerer, V., Mogler, L., Steitz, J. P., Bisel, P., Hess, C., Schoeder, C. T., Muller, C. E., Huppertz, L. M., Westphal, F., Schäper, J. and Auwärter, V. (2018) Structural characterization and pharmacological evaluation of the new synthetic cannabinoid CUMYL-PEGACLONE. Drug Test. Anal. 10, 597-603.

Banister, S. D., Stuart, J., Kevin, R. C., Edington, A., Longworth, M., Wilkinson, S. M., Beinat, C., Buchanan, A. S., Hibbs, D. E., Glass, M., Connor, M., McGregor, I. S. and Kassiou, M. (2015) Effects of bioisosteric fluorine in synthetic cannabinoid designer drugs $\mathrm{JWH}$ 018, AM-2201, UR-144, XLR-11, PB-22, 5F-PB-22, APICA, and STS-135. ACS Chem. Neurosci. 6, 1445-1458.

Behonick, G., Shanks, K. G., Firchau, D. J., Mathur, G., Lynch, C. F., Nashelsky, M., Jaskierny, D. J. and Meroueh, C. (2014) Four postmortem case reports with quantitative detection of the synthetic cannabinoid, 5F-PB-22. J. Anal. Toxicol. 38, 559-562.

Berkovitz, R., Arieli, M. and Marom, E. (2011) Synthetic cannabinoids-the new "legal high" drugs. Harefuah 150, 884-887, 937.

Brianna Sheppard, A., Gross, S. C., Pavelka, S. A., Hall, M. J. and Palmatier, M. I. (2012) Caffeine increases the motivation to obtain non-drug reinforcers in rats. Drug Alcohol Depend. 124, 216-222.

Budney, A. J. and Hughes, J. R. (2006) The cannabis withdrawal syndrome. Curr. Opin. Psychiatry 19, 233-238.

Burns, N., Theakstone, A., Zhu, H., O'Dell, L., Pearson, J., Ashton, T., Pfeffer, F. and Conlan, X. (2020) The identification of synthetic cannabinoids surface coated on herbal substrates using solid-state nuclear magnetic resonance spectroscopy. Anal. Chim. Acta 1104, 105-109.

Carliner, H., Brown, Q. L., Sarvet, A. L. and Hasin, D. S. (2017) Cannabis use, attitudes, and legal status in the U.S.: a review. Prev. Med. 104, 13-23.

Carlini, E. A. (2004) The good and the bad effects of (-) trans-delta9-tetrahydrocannabinol $(\triangle 9-\mathrm{THC})$ on humans. Toxicon 44, 461467.

Covey, D. P., Wenzel, J. M. and Cheer, J. F. (2015) Cannabinoid modulation of drug reward and the implications of marijuana legalization. Brain Res. 1628, 233-243.

De Luca, M. A., Bimpisidis, Z., Melis, M., Marti, M., Caboni, P., Valentini, V., Margiani, G., Pintori, N., Polis, I., Marsicano, G., Parsons, L. H. and Di Chiara, G. (2015) Stimulation of in vivo dopamine transmission and intravenous self-administration in rats and mice by JWH-018, a Spice cannabinoid. Neuropharmacology 99, 705-714.

Dei Cas, M., Casagni, E., Arnoldi, S., Gambaro, V. and Roda, G. (2019) Screening of new psychoactive substances (NPS) by gaschromatography/time of flight mass spectrometry (GC/MS-TOF) and application to 63 cases of judicial seizure. Forensic Sci. Int. Synergy 1, 71-78.

Dresen, S., Ferreiros, N., Putz, M., Westphal, F., Zimmermann, R. and Auwarter, V. (2010) Monitoring of herbal mixtures potentially containing synthetic cannabinoids as psychoactive compounds. J. Mass Spectrom. 45, 1186-1194.

Drug Enforcement Administration, Department of Justice (2016) Schedules of controlled substances: placement of PB-22, 5FPB-22, AB-FUBINACA and ADB-PINACA into schedule I. Final rule. Fed. Regist. 81, 61130-61133.

Dziadulewicz, E. K., Bevan, S. J., Brain, C. T., Coote, P. R., Culshaw, A. J., Davis, A. J., Edwards, L. J., Fisher, A. J., Fox, A. J., Gentry, C., Groarke, A., Hart, T. W., Huber, W., James, I. F., Kesingland, A., La Vecchia, L., Loong, Y., Lyothier, I., McNair, K., O’Farrell, C., Peacock, M., Portmann, R., Schopfer, U., Yaqoob, M. and Zadrobilek, J. (2007) Naphthalen-1-yl-(4-pentyloxynaphthalen-1-yl)methanone: a potent, orally bioavailable human CB1/CB2 dual agonist with antihyperalgesic properties and restricted central nervous system penetration. J. Med. Chem. 50, 3851-3856.

Fantegrossi, W. E., Moran, J. H., Radominska-Pandya, A. and Prather, P. L. (2014) Distinct pharmacology and metabolism of K2 synthetic cannabinoids compared to $\triangle(9)$-THC: mechanism underlying greater toxicity? Life Sci. 97, 45-54.

Fantegrossi, W. E., Wilson, C. D. and Berquist, M. D. (2018) Pro-psychotic effects of synthetic cannabinoids: interactions with central dopamine, serotonin, and glutamate systems. Drug Metab. Rev. 50, 65-73.

Fattore, L., Cossu, G., Martellotta, C. M. and Fratta, W. (2001) Intravenous self-administration of the cannabinoid CB1 receptor agonist WIN 55,212-2 in rats. Psychopharmacology 156, 410-416.

Gaoni, Y. and Mechoulam, R. (1964) Isolation, structure, and partial synthesis of an active constituent of hashish. J. Am. Chem. Soc. 86, 1646-1647.

Garcia, K. L., Le, A. D. and Tyndale, R. F. (2014) Effect of food training and training dose on nicotine self-administration in rats. Behav. Brain Res. 274, 10-18. 
Gatch, M. B. and Forster, M. J. (2015) $\Delta$ 9-Tetrahydrocannabinol-like effects of novel synthetic cannabinoids found on the gray market. Behav. Pharmacol. 26, 460-468.

Grigg, J., Manning, V., Arunogiri, S. and Lubman, D. I. (2019) Synthetic cannabinoid use disorder: an update for general psychiatrists. Australas. Psychiatry 27, 279-283.

Hájos, N., Ledent, C. and Freund, T. F. (2001) Novel cannabinoid-sensitive receptor mediates inhibition of glutamatergic synaptic transmission in the hippocampus. Neuroscience 106, 1-4.

Heath, T. S., Burroughs, Z., Thompson, A. J. and Tecklenburg, F. W. (2012) Acute intoxication caused by a synthetic cannabinoid in two adolescents. J. Pediatr. Pharmacol. Ther. 17, 177-181.

Hermanns-Clausen, M., Kneisel, S., Hutter, M., Szabo, B. and Auwarter, V. (2013a) Acute intoxication by synthetic cannabinoids--four case reports. Drug Test. Anal. 5, 790-794.

Hermanns-Clausen, M., Kneisel, S., Szabo, B. and Auwarter, V. (2013b) Acute toxicity due to the confirmed consumption of synthetic cannabinoids: clinical and laboratory findings. Addiction 108, 534-544.

Hur, K.-H., Kim, S.-E., Lee, B.-R., Ko, Y.-H., Seo, J.-Y., Kim, S.-K., Ma, S.-X., Kim, Y.-J., Jeong, Y., Pham, D. T., Trinh, Q. D., Shin, E. J., Kim, H. C., Lee, Y. S., Lee, S. Y. and Jang, C. G. (2020) 25C-NBF, a new psychoactive substance, has addictive and neurotoxic potential in rodents. Arch. Toxicol. 94, 2505-2516.

Inci, R., Kelekci, K. H., Oguz, N., Karaca, S., Karadas, B. and Bayrakci, A. (2017) Dermatological aspects of synthetic cannabinoid addiction. Cutan. Ocul. Toxicol. 36, 125-131.

Kirschmann, E. K., Pollock, M. W., Nagarajan, V. and Torregrossa, M. M. (2017) Effects of adolescent cannabinoid self-administration in rats on addiction-related behaviors and working memory. Neuropsychopharmacology 42, 989-1000.

Krotulski, A. J., Mohr, A. L. A., Kacinko, S. L., Fogarty, M. F., Shuda, S. A., Diamond, F. X., Kinney, W. A., Menendez, M. J. and Logan, B. K. (2019) 4F-MDMB-BINACA: a new synthetic cannabinoid widely implicated in forensic casework. J. Forensic Sci. 64, 1451-1461.

Langer, N., Lindigkeit, R., Schiebel, H. M., Ernst, L. and Beuerle, T. (2014) Identification and quantification of synthetic cannabinoids in 'spice-like' herbal mixtures: a snapshot of the German situation in the autumn of 2012. Drug Test. Anal. 6, 59-71.

Lawler, A. (2018) Cannabis, opium use part of ancient Near Eastern cultures. Science 360, 249-250.

Lefever, T. W., Marusich, J. A., Antonazzo, K. R. and Wiley, J. L. (2014) Evaluation of WIN 55,212-2 self-administration in rats as a potential cannabinoid abuse liability model. Pharmacol. Biochem. Behav. 118, 30-35.

Leffa, D. T., Ferreira, S. G., Machado, N. J., Souza, C. M., Rosa, F. D., de Carvalho, C., Kincheski, G. C., Takahashi, R. N., Porciúncula, L. O., Souza, D. O., Cunha, R. A. and Pandolfo, P. (2019) Caffeine and cannabinoid receptors modulate impulsive behavior in an animal model of attentional deficit and hyperactivity disorder. Eur. J. Neurosci. 49, 1673-1683.

Makriyannis, A. and Deng, H. (2007) Receptor selective cannabimimetic aminoalkylindoles. United States Patent US 7,173,027 B2. 2007 Feb 6.

Melvin, L. S., Milne, G. M., Johnson, M. R., Subramaniam, B., Wilken, G. H. and Howlett, A. C. (1993) Structure-activity relationships for cannabinoid receptor-binding and analgesic activity: studies of bicyclic cannabinoid analogs. Mol. Pharmacol. 44, 1008-1015.
Murray, R. M., Englund, A., Abi-Dargham, A., Lewis, D. A., Di Forti, M., Davies, C., Sherif, M., McGuire, P. and D'Souza, D. C. (2017) Cannabis-associated psychosis: neural substrate and clinical impact. Neuropharmacology 124, 89-104.

Nacca, N., Vatti, D., Sullivan, R., Sud, P., Su, M. and Marraffa, J. (2013) The synthetic cannabinoid withdrawal syndrome. J. Addict. Med. 7, 296-298.

Osborne, G. B. and Fogel, C. (2008) Understanding the motivations for recreational marijuana use among adult Canadians. Subst. Use Misuse 43, 539-572; discussion 573-579, 585-587.

Ozten, M., Erol, A., Karayilan, S., Kapudan, H., Orsel, E. S. and Kumsar, N. A. (2015) Impulsivity in bipolar and substance use disorders. Compr. Psychiatry 59, 28-32.

Papaseit, E., Farre, M., Schifano, F. and Torrens, M. (2014) Emerging drugs in Europe. Curr. Opin. Psychiatry 27, 243-250.

Pertwee, R. G., Howlett, A. C., Abood, M. E., Alexander, S. P. H., Di Marzo, V., Elphick, M. R., Greasley, P. J., Hansen, H. S., Kunos, G., Mackie, K., Mechoulam, R. and Ross, R. A. (2010) International Union of Basic and Clinical Pharmacology. LXXIX. Cannabinoid receptors and their ligands: beyond $\mathrm{CB}_{1}$ and $\mathrm{CB}_{2}$. Pharmacol. Rev. 62, 588-631

Pryce, G. and Baker, D. (2017) Antidote to cannabinoid intoxication: the CB1 receptor inverse agonist, AM251, reverses hypothermic effects of the CB1 receptor agonist, CB-13, in mice. Br. J. Pharmacol. 174, 3790-3794

Sarıbaş, Ş. E. and Ulugöl, A. (2014) Struggle with bonzai: a review on synthetic cannabinoid abuse. Turk. Med. Stud. J. 1, 86-93.

Solinas, M., Panlilio, L. V., Tanda, G., Makriyannis, A., Matthews, S. A. and Goldberg, S. R. (2005) Cannabinoid agonists but not inhibitors of endogenous cannabinoid transport or metabolism enhance the reinforcing efficacy of heroin in rats. Neuropsychopharmacology 30, 2046-2057.

Spano, M. S., Fattore, L., Cossu, G., Deiana, S., Fadda, P. and Fratta, W. (2004) CB1 receptor agonist and heroin, but not cocaine, reinstate cannabinoid-seeking behaviour in the rat. Br. J. Pharmacol. 143, 343-350.

Tai, S. and Fantegrossi, W. E. (2014) Synthetic cannabinoids: pharmacology, behavioral effects, and abuse potential. Curr. Addict. Rep. 1, 129-136.

Uchiyama, N., Kawamura, M., Kikura-Hanajiri, R. and Goda, Y. (2012) Identification of two new-type synthetic cannabinoids, $\mathrm{N}$-(1adamantyl)-1-pentyl-1H-indole-3-carboxamide (APICA) and $\mathrm{N}$-(1adamantyl)-1-pentyl-1H-indazole-3-carboxamide (APINACA), and detection of five synthetic cannabinoids, AM-1220, AM-2233, AM1241, CB-13 (CRA-13), and AM-1248, as designer drugs in illegal products. Forensic Toxicol. 30, 114-125.

Weissman, A., Milne, G. M. and Melvin, L. S., Jr. (1982) Cannabimimetic activity from CP-47,497, a derivative of 3-phenylcyclohexanol. J. Pharmacol. Exp. Ther. 223, 516-523.

Wise, R. A. and Koob, G. F. (2014) The development and maintenance of drug addiction. Neuropsychopharmacology 39, 254-262.

Wiskerke, J., Van Mourik, Y., Schetters, D., Schoffelmeer, A. and Pattij, T. (2012) On the role of cannabinoid CB1- and $\mu$-opioid receptors in motor impulsivity. Front. Pharmacol. 3, 108.

Zimmermann, U. S., Winkelmann, P. R., Pilhatsch, M., Nees, J. A., Spanagel, R. and Schulz, K. (2009) Withdrawal phenomena and dependence syndrome after the consumption of "spice gold". Dtsch. Arztebl. Int. 106, 464-467. 